\title{
Necrotising myometrial granulomas leading to postpartal hemorrhage: an extremely unusual presentation
}

\author{
Mansi Chandna*, Meeta Singh, Garima Singh, Leela Pant
}

Department of Pathology, North Delhi Municipal Corporation Medical College and Hindu Rao Hospital, Delhi, India

Received: 18 June 2016

Accepted: 08 July 2016

*Correspondence:

Dr. Mansi Chandna,

E-mail: chandnamansi@gmail.com

Copyright: (c) the author(s), publisher and licensee Medip Academy. This is an open-access article distributed under the terms of the Creative Commons Attribution Non-Commercial License, which permits unrestricted non-commercial use, distribution, and reproduction in any medium, provided the original work is properly cited.

\begin{abstract}
Granulomas exclusively involving the myometrium are rare pathological finding and those presenting with atonic post-partum hemorrhage have never been reported. Here we present a case of myometrial granulomas presenting with atonic postpartum hemorrhage (PPH) with no evidence of granulomatous inflammation elsewhere in the body. There was also no history of instrumentation or biopsy of the uterine cavity in the past.
\end{abstract}

Keywords: Granuloma, Myometrium, Postpartum hemorrhage

\section{INTRODUCTION}

Granulomas involving uterus can be seen in various pathological conditions. ${ }^{1,2}$ These include infections like tuberculosis, atypical mycobacteria, endemic mycosis, actinomycosis and parasites. Non-infectious causes include foreign body reactions, sarcoidosis and vasculitis. Focal granulomas are related to previous biopsy or surgery. ${ }^{3}$ Rare cases are seen with necrobiosis and talc. ${ }^{4,5}$ Most of these conditions cause granulomatous inflammation of the endometrium. Granuloma exclusively involving myometrium is a very rare entity. Here we present a case with necrotising granuloma in myometrium presenting with atonic post-partum hemorrhage.

\section{CASE REPORT}

A 27 year old female in labour presented in obstetric emergency of our hospital. Patient went into uncontrolled atonic post-partum hemorrhage immediately after delivery, thus, hysterectomy was performed. The hysterectomy specimen was sent for histopathological examination. On histology, endometrium showed decidua only. Products of conception were not seen. Multiple necrotising (caseating) confluent epitheloid cell granulomas were seen in the myometrium. Though, the stain for acid fast bacilli was negative, possibility of tuberculosis was strongly suggested. The specimen was thoroughly sampled to rule out involvement of endometrium or cervix by tuberculosis; however with negative results.

On-going through the medical records, there was no history of instrumentation and previous surgery. Chest $\mathrm{x}-$ ray was within normal limit. A detailed clinical and radiological work up for tuberculosis elsewhere, sarcoidosis and vasculitis were negative.

Thus, a final diagnosis of necrotizing granuloma myometrium, most likely tubercular, presenting with atonic post-partal haemorrhage was suggested. Thus making it a first case reported of such a condition.

\section{DISCUSSION}

Granulomas involving myometrium are uncommon and those leading to atonic post-partum haemorrhage have not been reported in literature before. A variety of conditions are associated with post-partum haemorrhage including uterine atony, retained placenta, lower genital tract laceration, consumptive coagulopathy and acute 
inversion of uterus and many others. ${ }^{6}$ Subinvolution of uterus due to infection can be a cause of secondary postpartum hemorrhage (PPH). They are usually the ascending infections caused by vaginal flora. These include streptococci, peptostreptococci, bacteroides, E.coli and Chlamydia. ${ }^{7}$ Tuberculosis has not been mentioned as a cause of secondary or primary $\mathrm{PPH}$ earlier.

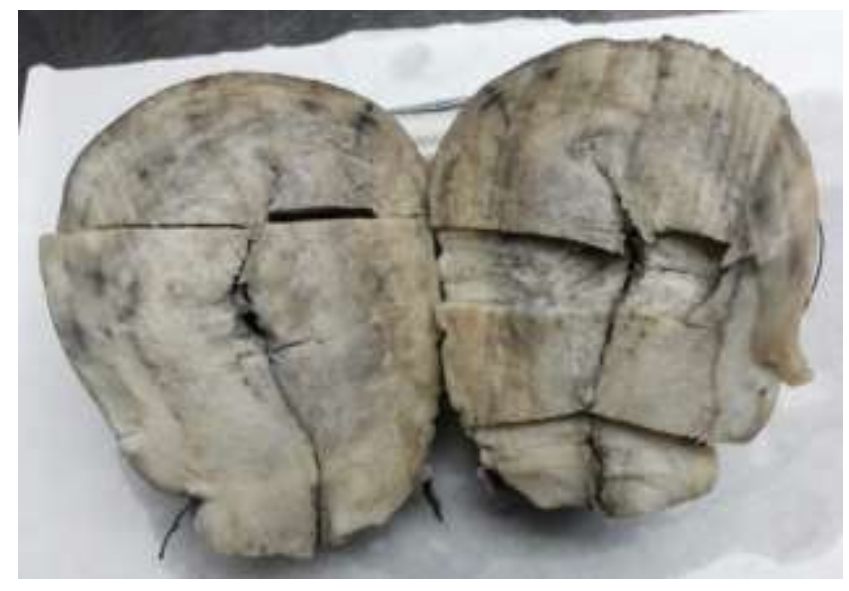

Figure 1: Cut surface of uterus showing multiple grey white patchy areas in myometrium.

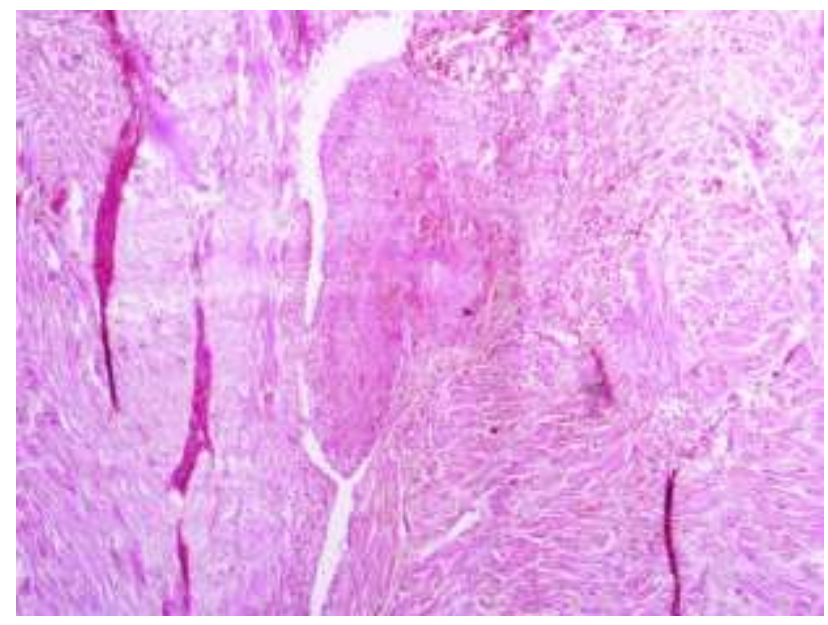

Figure 2: Photomicrograph showing necrotising granulomas in myometrium (H \& E; 40X).

Granulomatous inflammation of myometrium can be focal or diffuse. Focal lesions are usually associated with a previous history of instrumentation. Diffuse granulomas may be found throughout the female genital tract (FGT) associated with mycobacterium tuberculosis and are commonest in endometrium. Involvement of myometrium is seen in only $20 \%$ of cases and always associated with granulomas elsewhere in the FGT, most likely endometrium. ${ }^{8}$ Isolated myometrial involvement has not been reported in the literature before.

Sinha et al reported a case of diffuse myometrial granulomas associated with tuberculosis presenting with menorrhagia. On ultrasonography, multiple, well-defined anechoic areas were seen in the myometrium. Diagnosis of tuberculosis was made on endometrial curettage, unlike the present case, and patient was started on antitubercular treatment. After completion of treatment, patient was relieved of menorrhagia and repeat ultrasonography revealed homogenous myometrium. ${ }^{9}$

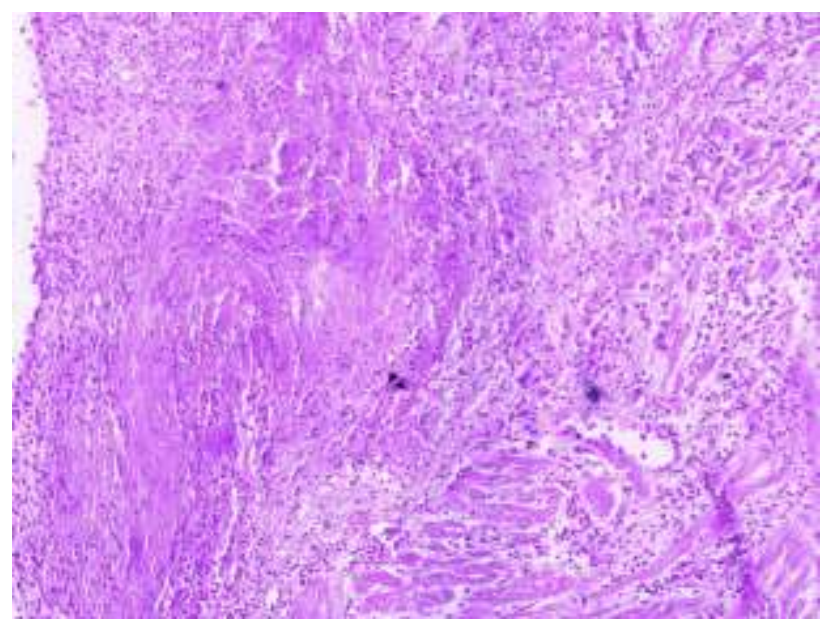

Figure 3: Photomicrograph at high power showing caseating granuloma in myometrium (H \& E; 100X).

In a 10 year retrospective study by Almoujahed et al on utrine granulomas showed uterine corpus granulomas in $18 / 1200$ cases $(0.15 \%)$. Focal granulomas were seen in serosa $(n=4)$, myometrium $(n=4)$ and endometrium $(n=4)$. These isolated granulomas in the myometrium were associated with a previous history of caesarean section (75\%), dilatation and curettage (75\%), endometrial biopsy $(25 \%)$ and any other biopsy or surgery (100\%). Most common clinical presentation was abnormal uterine bleeding (30\%) followed by abnormal cytology and pelvic pain. ${ }^{3}$ None of which were present in our case.

Another study by Hoff et al comprised 11 cases of incidental uterine granulomas and only 1 out of 11 had non-necrotising myometrial granulomas. 8 out of 11 were associated with previous history of instrumentation. Stain for acid fast bacilli were not positive in any of the case. None of the patient had any clinical or laboratory evidence of tuberculosis, fungal infections or sarcoidosis. Most common presenting complaint was uterine bleeding. 10

Thus we can conclude that pure myometrial tuberculosis is an extremely rare entity and that leading to post partal haemorrhage is even rarer. A proper search must be made to exclude all the possible cause of granulomatous inflammation before reaching a final diagnosis.

Funding: No funding sources

Conflict of interest: None declared

Ethical approval: Not required 


\section{REFERENCES}

1. Zumla A, James G. Granulomatous infections: etiology and classification. Clin Infect Dis. 1996;23:146-58.

2. Williams GT, Williams WJ. Granulomatous inflammation: a review. J Clin Pathol. 1983;36:72333.

3. Almoujahed MO, Briski LE, Prysak M, Johnson LB, Khatib R. Uterine granulomas: Clinical and pathological features. Am J Clin Pathol. 2002;117:771-5.

4. Evans CS, Goldman RL, Klein HZ, Kohout ND. Necrobiotic granulomas of the uterine cervix. A probable postoperative reaction. Am J Surg Pathol. 1984;11:841-4.

5. Shustin L, Haviv YS, Weinberger M, Safadi R. Talc granuloma of the uterus. Eur J Med Res. 1995;1:4950 .

6. Klufio CA, Amoa AB, Kariwiga G. Primary postpartum haemorrhage: causes, etiological risk factors, prevention and management. P N G Med J. 1995;38(2):133-49.

7. Klein TA, Richmond JA, Mishell DR Jr.Pelvic tuberculosis. Obstet Gynecol. 1976;48:99-104.

8. Nogales-Ortiz F, Tarancon I, Nogales FF Jr. The pathology of female genital tuberculosis. Obstet Gynecol. 1979;53:422-8.

9. Sinha R, Gupta D Tuli N. Genital tract tuberculosis with myometrial involvement. Int J Gynecol Obstet. 1997;57:191-2.

10. Hoff E, Prayson RA. Incidental granulomatous inflammation of the uterus. South Med J. 2002;95:884-8.

Cite this article as: Chandna M, Singh M, Singh G, Pant L. Necrotising myometrial granulomas leading to postpartal hemorrhage: an extremely unusual presentation. Int J Reprod Contracept Obstet Gynecol 2016;5:2875-7. 